\title{
Net Energy Analysis of Gas Production from the Marcellus Shale
}

\author{
Devin Moeller $^{1} \cdot$ David Murphy $^{2}$
}

Received: 1 May 2016/Accepted: 7 July 2016/Published online: 15 July 2016

(C) Springer International Publishing Switzerland 2016

\begin{abstract}
Total production of dry natural gas in the USA increased to $24.4 \mathrm{Tcf}$ in 2013, a $35 \%$ increase from 2005 levels. This increase was largely a result of the rapid development of shale resources in the lower 48 states. The Marcellus play alone accounted for nearly $15 \%$ of the total dry gas produced in 2013. In this study, we calculate the energy return on investment (EROI) using a hybrid lifecycle analysis approach bounded by three process stages: (1) $E{ } I_{P \& P}$, which includes production and processing energetic costs; (2) $\mathrm{EROI}_{\mathrm{P}, \mathrm{P} \& \mathrm{~T}}$, which considers production, processing, and transportation; and (3) $\mathrm{EROI}_{\mathrm{GRID}}$, which includes the energetic costs associated with electricity generation. Most significantly, the inclusion of electricity generation within the EROI analysis makes possible a functional unit comparison to alternative sources of energy into the power grid. Well pad preparation and well drilling had the largest energy costs of all the upstream process stages, accounting for nearly $75 \%$ of production and processing costs. However, the largest energy consumer among the process stages is the cost associated with electricity production, and our model assumes $43 \%$ power plant efficiency, accounting for nearly $94 \%$ of the total energy costs of producing electricity from natural gas. Defined by process stage, our analysis calculated an

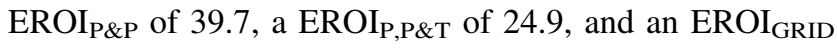

Devin Moeller and David Murphy contributed equally to this work.

Devin Moeller

dmoeller@niu.edu

1 Department of Geography, Northern Illinois University, DeKalb, IL, USA

2 Environmental Studies Department, St. Lawrence University, Canton, NY, USA

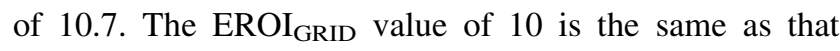
calculated for photovoltaic systems, indicating that shale gas, when burned for electricity, provides similar net energy benefits to society as an average PV system.

Keywords Net energy - EROI - Life cycle assessment . Shale gas $\cdot$ Marcellus

\section{Introduction}

Unconventional gas and oil production has revolutionized the energy landscape in the USA Currently, oil production from tight oil resources accounts for $42 \%$ of total US production, up from $5 \%$ in 2009. Similarly, natural gas from shale resources accounts for $46 \%$ of total US production, up from $14 \%$ in 2009 (EIA 2015). Perhaps more importantly, the USA is endowed with numerous shale resources and the EIA projects that the recent increase in production will continue far into the future, especially in the case of shale gas which is forecasted to have production surpassing 19 trillion cubic feet (Tcf) annually by 2040 (EIA 2015).

From an economic perspective, the utility of an energy resource lies in its ability to produce net energy for the economy, i.e., the "profit" energy yielded from a resource after accounting for the energy required in the extraction process (Hall et al. 2009). In fact, most of the major energy resources utilized over the past century have had net energy ratios (NERs, also known as energy return on investment, or energy return on energy invested) greater than 20 and sometimes as high as 80 (Murphy et al. 2011). This is significant because when the EROI of an energy producing process falls below roughly 10, the net energy delivered to society from that process begins to decline exponentially. This exponential decline is known as the net energy cliff 
(Hall et al. 2009; Murphy et al. 2011; Murphy 2014; Mearns 2008).

From a policy perspective, it is important to pursue technologies that have EROIs above 10 and thus avoid the low net energy returns. Therefore, as the USA continues the transition to tight oil and shale gas, it is important to understand how the net energy provided from those resources is also changing (Murphy et al. 2011). There have been a few analyses to date that have provided NERs for shale gas resources (Aucott and Melillo 2013; Yaritani and Matsushima 2014). Though these estimates add to the literature base, they measure only the EROI at the well gate (Aucott and Melillo 2013), or process-gate level (Yaritani and Matsushima 2014), meaning that they only measure costs up until the gas leaves the well site or processing plant, respectively. Using the well gate or process gate as a boundary is not problematic in and of itself, but it does become an issue when trying to compare EROI results across energy resources. For example, comparing an EROI of shale gas that has a boundary at the well gate with that of photovoltaic panels is problematic because the outputs being compared, i.e., natural gas leaving a well pad and electricity entering the grid, are fundamentally different. Indeed, it is due to this incompatibility that the ISO 14040 standards require the specification of a functional unit, i.e., a unit upon which an analysis can be based and can therefore allow for comparisons across different analyses. The lack of consistent functional units in the net energy literature is pervasive and has been discussed at length by Raugei et al. (2012).

The main objective of this analysis is to calculate the net energy ratio for shale gas in a way that allows for comparison with other resources and technologies. To do this, we first analyzed production data and data on the energy costs of production to calculate the NER for average wells in the Marcellus Shale. We then compared our estimates to those in the literature that use similar functional units to compare shale gas with photovoltaics (PV).

\section{Current Literature on the Energy Return Ratios}

Over the past 10 years, there has been a surge in the amount of research investigating various energy return ratios for energy extraction techniques and technologies. Probably, the most popular ERR is the energy return on investment metric, developed by Hall et al. (1981). Gagnon et al. (2009) estimated the EROI of global oil and gas production and found that it has been in decline since about the early 2000s. Since then, other analyses, like those of Guilford et al. (2011), have concluded that the EROI of oil and gas has had increases and decreases over the past century between 8 and 23 and has been in decline since roughly 2000. These results echo those of Cleveland (2005) who found that the EROI of US oil production had a maximum in the 1960 s of 19 and a minimum of 7 , with a declining trend from the early to mid-1990.

In addition to these studies on conventional oil and gas production, there have been a number of studies of the newer unconventional plays. Brandt et al. (2013) found that oil sands production has an energy return of 6 at the mine mouth and 3 at the point of use. Brandt (2011) found that the returns from depleted oil fields in California were similarly between 3.5 and 6.5. Sell et al. (2011) found the EROI of a tight gas well in the Appalachian Basin to be roughly between 67 and 120 .

Of most relevance to this study are the previous analyses of the EROI of shale gas production from the Marcellus Shale. Aucott and Melillo (2013) found that the EROI of a typical Marcellus well was between 64 and 112. Yaritani and Matsushima (2014) measured an EROI at the wellhead for shale gas production as between 13 and 23, with an average of 17 . They also note that the average value drops to 13 when measured at the point of use. The difference between the lower EROI values reported in Yaritani and Matsushima (2014) seems to derive from the energy inputs assigned to "lease/plant energy" which are roughly $60 \%$ of the total energy inputs in the Yaritani and Matsushima (2014) analysis. Lease/plant energy is the energy consumed at both the production site and processing plant. Yaritani and Matsushima (2014) derive their energy input total from available carbon release data for both processing stages, leading to energy costs associated with emission factors rather than direct energy inputs. Aucott and Melillo (2013), for example, do not include an energy input value for this process.

The difference in EROI between Aucott and Melillo (2013) and Yaritani and Matsushima (2014) is directly tied to the fact that each study used different boundaries for their calculation of EROI. Aucott and Melillo have a tighter boundary, ending at the well gate, while Yaritani and Matsushima have a wider boundary ending at the process gate. As expected, since Yaritani and Matsushima have a wider boundary, they include more energy inputs and have a correspondingly lower EROI.

Another way to think about the difference in boundaries is through the concept of a functional unit. The functional unit in the Aucott and Melillo analysis is a unit of natural gas delivered to a regional gathering pipeline, i.e., a unit of natural gas leaving the well pad. The functional unit in the Yaritani and Matsushima (2014) analysis, on the other hand, is a unit of natural gas delivered to a main trunk pipeline, i.e., unit of natural gas leaving the processing plant. The fact that these functional units are different means that we cannot compare the EROI numbers directly.

This analysis seeks to provide clarity to this literature by calculating an EROI for shale gas using three different 
boundary stages. The first EROI is called EROI $I_{P \& P}$, which means the EROI of shale gas through the production and on-site processing, which is akin to the Aucott and Melillo (2013) boundary. The second is $\mathrm{EROI}_{\mathrm{P}, \mathrm{P} \& \mathrm{~T}}$, which is the EROI of shale gas production through production, processing, and transportation, which is comparable to the Yaritani and Matsushima (2014) boundary. The third is the EROI $_{\mathrm{GRID}}$, which is the EROI of shale gas production through the conversion of that gas into a megajoule (MJ) of electricity fed into the grid, which is same functional unit used in most EROI analyses of renewable energy technologies.

\section{Methods}

We calculated the EROI of shale gas production by estimating both the energy produced from the average shale well from the actual shale gas production statistics reported by the Pennsylvania Department of Environmental Protection (PA DNR), and the energy consumed to produce that energy. The energy inputs used to produce the shale gas were derived from values reported in a number of different LCA analyses, including. (Burnham et al. 2011; Clark et al. 2011, 2013; Jiang et al. 2011; Stokes and Horvath 2006). For this study, emphasis is placed on the model developments of Jiang et al. (2011) and Clark et al. (2011).

Jiang et al. (2011) performed a greenhouse gas LCA on gas extraction process in the Marcellus Shale using the Carnegie-Mellon economic input-output (EIO) framework (Carnegie-Mellon 2010). Clark et al. (2011) performed an LCA on the same process but used the Greenhouse gases, Regulated Emissions, and Energy use in Transportation (GREET) model produced by Argonne National Laboratory (Wang 2008). While each approach offers a unique perspective to the identification of boundaries within the production process and is specifically used for evaluating GHG emissions, the fundamental inputs required in these GHG-LCAs are the same as those needed in our research.

The approaches diverge in the methodology of quantifying the inputs within what are called "process stages." The process-based LCA approach, which is used by Clark et al. (2011), places a boundary around each process stage and then itemized the energy input and outputs within the boundary of the activity. For example, in the well drilling stage the energy content of the materials required for the well casing, drilling mud, and the diesel fuel used for drilling and transportation are included as energetic inputs. Jiang et al. (2011), on the other hand, used an EIO approach which uses financial cost data for specific processes and multiplies them by energy intensity factors, resulting in energy units. The energy intensity factors are generated by an input-output table with hundreds of economic sub-sectors. The advantage for the process-based approach is that all inputs and outputs within the boundary are accounted for, and these are generally the direct energy inputs and outputs of a process. The disadvantage is that the indirect inputs and outputs fall generally outside the boundary of analysis and are therefore ignored. The advantages and disadvantages of the EIO approach are almost opposite; i.e., the EIO approach is coarser and may not capture all direct and indirect energy inputs and outputs, but the indirect energy in a process stage is accounted for in the I-O framework used to generate the energy intensity ratios.

The hybrid LCA-EIO approach used here merges the best parts of both frameworks; i.e., the process method is used to assess all the direct energy inputs and outputs, while the EIO framework is used to assess upstream and downstream indirect costs.

\section{Boundaries of Analysis}

Using a modeled schematic of the pre-production and postproduction processes adapted from Jiang et al. (2011) and Clark et al. (2011), our model (a hybrid LCA approach) is, at its core, a cost-benefit analysis at the energy unit level (Fig. 1).

\section{Well Production Data}

The analysis of well production data includes 5119 active wells in Pennsylvania located throughout the Marcellus

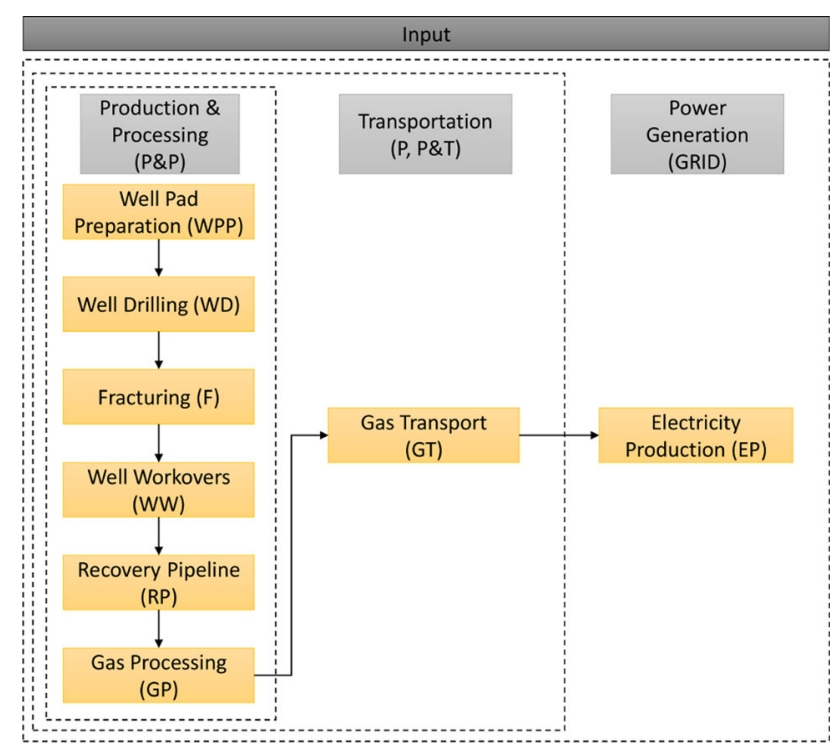

Fig. 1 Analysis process stage boundaries 
Shale play, and EUR values were estimated through decline curve analysis. The PA DNR collects well data in 6-month production periods, reporting average daily production within each period. The time horizon of the analysis is from January 2010 to July 2014 and includes only those active wells with an initial production (IP) period (first 6 months) within the designated time frame. The mean EUR of the wells included in the study is 3.16 billion cubic feet (Bcf), nearly $80 \%$ of the wells analyzed are within \pm 1 standard deviation from the mean, $9 \%$ of the wells were calculated as having an EUR of less than one standard deviation from the mean value, and $12 \%$ of the wells studied reported production greater than one standard deviation (Table 1).

\section{Decline Curve Analysis: Estimated Ultimate Recoverable Gas per Well}

The average EUR value is extrapolated from the average production values over a 4-year period (eight 6-month periods) and extended to a 30-year time horizon. Although the EUR is calculated based on the 30-year production well life, it is interesting to note that the average well included in the analysis produced $97 \%$ of its EUR within the first 7 years of production. The available production values are fit to an exponential curve, where resulting average EUR is 3.16 Bcf (Fig. 2). The exponential estimate in the decline curve equation is derived from the available data and overestimates production values, as subsequent production periods are expected to decline more rapidly. In the first production period (January 2010 through June 2010), 821 wells began producing natural gas at an average of $1855 \mathrm{Mcf} /$ Day. In the second producing period (July 2010 through December 2010), 430 newly active wells began producing at an average IP of $3480.66 \mathrm{Mcf} / \mathrm{Day}$. Through advancements in technology and industry learning, the average IP levels from period one to period eight increased $245 \%$ (from 1855 to $6392.17 \mathrm{Mcf} /$ Day). Looking at yearover-year average IP change also offers clues about the resource base. For example, the greatest increase in average IP occurred from period one (January-June 2010) to period two (July-December 2010; an $88 \%$ increase in average IP values), while the average increase from period seven (January-June 2013) to period eight (July-December 2013) is $19 \%$, indicating diminishing marginal returns (Fig. 3).

\section{Energy Costs per Process Stage}

\section{Well Pad Preparation}

The well pad preparation inputs were provided by Jiang et al. (2011); the CMU model provides energy content equivalents based on per unit costs in 2002 USD (CMU GDI, 2010). The total average cost for well pad preparation is estimated at $\$ 3.2 \mathrm{M}$ (Jiang et al. 2011), and the CMU EIO model, utilizing an energy intensity ratio of $8.26 \mathrm{TJ} /$ $\$ 1 \mathrm{M}$, yields an energy input of $26.33 \mathrm{TJ}$. Far and away, the most energy-intensive process during well pad preparation is construction of the slurry trench, accounting for
Table 1 Estimated ultimate recoverable (EUR) of analyzed Marcellus wells

Fig. 2 Exponential decline curve for average well

\begin{tabular}{llcc}
\hline Description & EUR (Bcf) & Weight $(\%)$ & Energy content (TJ) \\
\hline Less than one SD & 0.23 & 9 & 253.47 \\
Mean & 3.16 & 79 & 3427.34 \\
Greater than one SD & 6.03 & 12 & 6539.92 \\
\hline
\end{tabular}

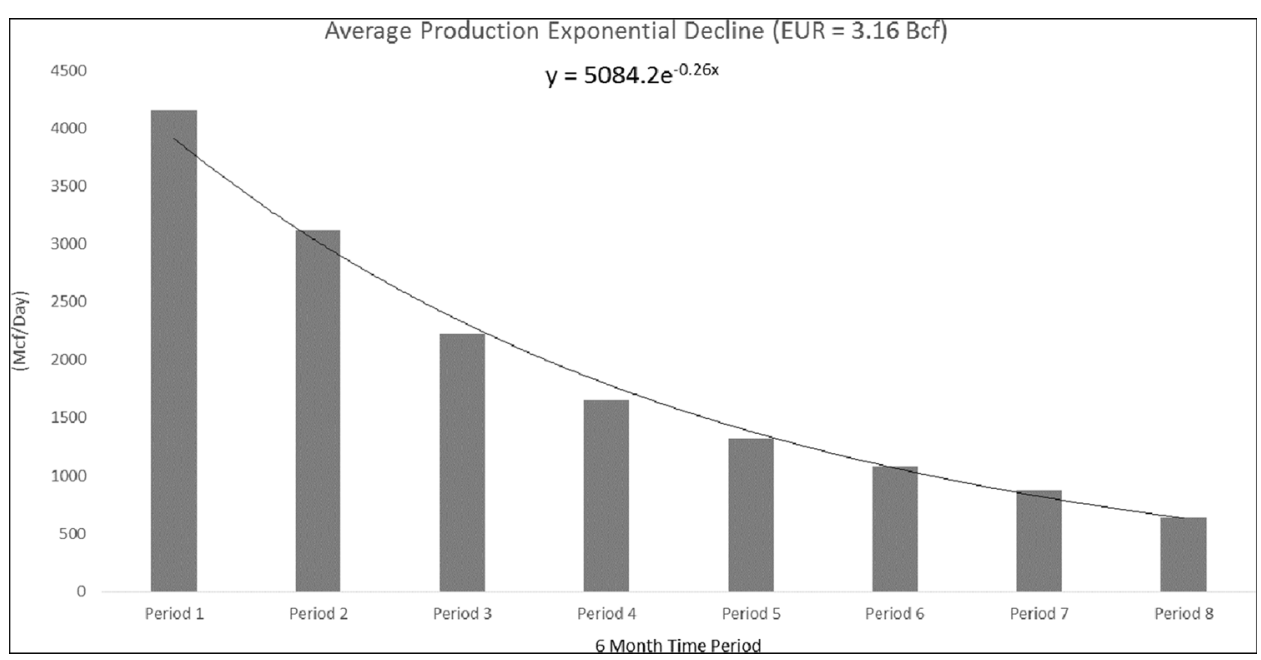


$75 \%$ of the total energy cost. The slurry trench is a waste site remediation requirement for the containment of subsurface pollutants and fracking flow-back water during well drilling and completion, and produced water from initial natural gas production (Table 2).

\section{Well Drilling}

The direct materials required for well drilling are based on per well estimates provided by Clark et al. (2011). Energy content for the steel and cement used in the well casings

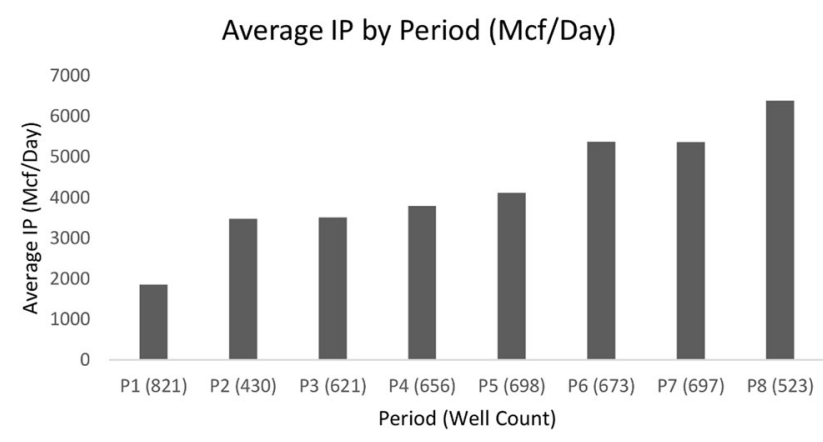

Fig. 3 Average initial production by period was obtained from the literature within the respective industries. According to Stubbles (2000), the energy content per metric ton of steel is $17.29 \mathrm{GJ} / \mathrm{MT}$, while Choate (2003) estimated the energy content of cement and gilsonite at $5.97 \mathrm{GJ} / \mathrm{MT}$. Admittedly, as the processes involved in manufacturing both cement and gilsonite vary widely across the industry, it is important to note that cement and gilsonite contribute only minimally to the total direct material cost involved in producing the well casings, at 11.81 and $0.41 \%$, respectively. Diesel fuel consumption (Jiang et al. 2011) includes both average water transportation and average drilling estimates. Steel production and diesel fuel consumption represent the bulk of the direct material and energy costs associated with well drilling, at 20.71 and $66.50 \%$. The average cost per component of the drilling mud was estimated by Jiang et al. (2011) at \$105/ MT and equated to a total energy drilling mud cost of $78.76 \mathrm{GJ}$, which contributes $0.65 \%$ to the remaining total direct drilling cost (Table 3). Jiang et al. (2011) estimate that the average total drilling cost per well within Marcellus is $\$ 2.2 \mathrm{M}$, at an intensity ratio of $11.40 \mathrm{TJ} / \$ 1 \mathrm{M}$, and is equivalent to $25.16 \mathrm{TJ}$ of total energy costs, which can be further segmented into $12.15 \mathrm{TJ}$ of total direct energy costs itemized in table five. The remaining $13.01 \mathrm{TJ}$

Table 2 Materials used in well pad preparation

\begin{tabular}{|c|c|c|c|c|}
\hline Item & Unit & Quantity & Total cost $(2002 \$)$ & Energy content $(\mathrm{TJ})$ \\
\hline \multicolumn{5}{|l|}{ Site clearing } \\
\hline Grub stumps and removal & Acre & 5 & 6793 & 0.0561 \\
\hline Cut and chip heavy trees & Acre & 5 & 21,185 & 0.1750 \\
\hline Grading & Square yard (SY) & 24,000 & 69,412 & 0.5733 \\
\hline \multicolumn{5}{|l|}{ Ponds } \\
\hline Slurry trench & Cubic feet (CF) & 100,000 & $2,385,581$ & 19.7049 \\
\hline Pond liners & Square feet (SF) & 22,000 & 28,774 & 0.2377 \\
\hline Stone pavement & Square yard (SY) & 24,000 & 319,428 & 2.6385 \\
\hline Storage tanks $(50,000$ gallons $)$ & Each & 2 & 356,942 & 2.9483 \\
\hline Total material cost & & & $3,188,116$ & 26.3338 \\
\hline
\end{tabular}

Table 3 Materials used in well drilling

\begin{tabular}{lrll}
\hline Material & Amount & Unit & Energy content (TJ) \\
\hline Direct costs & & & \\
Steel (type TBD) & 145.45 & Metric ton & 2.5156 \\
Portland cement & 238.68 & Metric ton & 1.4247 \\
Gilsonite (asphaltite) & 8.32 & Metric ton & 0.0497 \\
Diesel fuel & 55080.00 & Gallon & 8.0779 \\
Bentonite & 43.77 & Metric ton & 0.0739 \\
Soda ash & 0.72 & Metric ton & 0.0012 \\
Polypac & 1.43 & Metric ton & 0.0024 \\
Xanthan gum & 0.72 & Metric ton & 0.0012 \\
Total direct costs & & & 12.1467 \\
\hline
\end{tabular}


Table 4 Fuel and electricity requirements for management of Fracking fluid

Table 5 Hydraulic fracturing additives

\begin{tabular}{lclc}
\hline Item & Amount & Conversion & Energy content (GJ) \\
\hline Diesel fuel consumption (gal/well) & 4444 & $1 \mathrm{Gal}$ diesel $=146.33 \mathrm{MJ}$ & 650.29 \\
Electricity consumption (kWh/well) & 659 & $1 \mathrm{kWh}=3.6 \mathrm{MJ}$ & 2.37 \\
Total & & & 652.66 \\
\hline
\end{tabular}

\begin{tabular}{lclc}
\hline Component type & Cost $(\$ 2002)$ & Energy intensity $(\mathrm{TJ} / \$ 1 \mathrm{M})$ & Energy content $(\mathrm{GJ})$ \\
\hline Proppant & 22,000 & 21.6 & 475.20 \\
Petroleum distillate & 3000 & 32.4 & 97.20 \\
Inorganic matter & 3000 & 45.3 & 135.90 \\
Organic matter & 8000 & 17.4 & 139.20 \\
Total & & & 847.50 \\
\hline
\end{tabular}

$(25.16 \mathrm{TJ}-12.15 \mathrm{TJ})$ is allocated to the indirect energy costs associated with well drilling.

\section{Hydraulic Fracturing}

The hydraulic fracturing process stage includes two components: the energy costs associated with the management of fracturing fluid and the production of additives within the fracturing fluid. The average water requirement per well per fracturing job within the Marcellus Shale is $4.65 \mathrm{M}$ gallons. The diesel fuel consumed during the fracturing process is estimated at 4444 gallons per well (Clark et al. 2011), converted to an energy equivalent of 650.29 GJ. The average electricity consumption per fracturing job is $659 \mathrm{kWh}$ per well, equivalent to 2.37 GJ. The total energy costs associated with the management of hydraulic fracturing fluid per well per fracturing job are 652.66 GJ (Table 4). The second energy component associated with hydraulic fracturing is the estimate of hydraulic fluid additives. Fracturing fluid is specific to each individual well. Jiang et al. (2011) provide a generalized estimate of four primary compounds associated with typical multistage fracturing activity, which include: (1) (EIA 2015) proppant; (2) petroleum distillate; (3) inorganic matter; and (4) organic matter. The dollar cost associated with each primary compound is calculated based on individual component inputs (generalized from industry data) and valued at current market prices (Jiang et al. 2011). Based on energy intensity ratios, the CMU model calculates the energy equivalent of additive production at 847.50 GJ (Table 5). In total, the energy cost equivalent per well per fracturing job within the hydraulic fracturing process stage is $1.5 \mathrm{TJ}(652.66 \mathrm{GJ}+847.50 \mathrm{GJ})$.

\section{Well Workover}

The number of workovers required on an individual well depends on the geology of the well, well depth and length, the rate of production, and the time horizon of the producing well (Clark et al. 2011). Well workovers may include additional hydraulic fracturing jobs, cleaning of the casing, or possibly the installation of new production tubing. Because of the nascent nature of the industry, and uncertainty surrounding the time horizon for production in shale gas wells in the Marcellus Shale that use high-volume hydraulic fracturing (HVHF), it is difficult to project well workovers with much certainty. According to Clark et al. (2011), the industry estimates two workovers per well over its lifetime, and in this case workover refers to re-fracking the well and installation of new production tubing. As a proxy for the installation of new production tubing, the model includes the direct material (less drilling mud) energy costs calculated in the well drilling boundary stage. The total direct material energy costs associated with the well workover is $12.06 \mathrm{TJ}$. In total, the well workover process stage energy cost equivalent is $13.57 \mathrm{TJ}$.

\section{Recovery Pipeline}

The estimation of energy costs within the recovery pipeline focuses on the installation of the pipeline that feeds into the compressor stations and is adapted from the Clark et al. (2011) study. The material costs considered in pipeline construction are steel and diesel fuel consumption. The amount each is utilized in construction is a function of average EUR, where steel is measured in $\mathrm{Mg} / \mathrm{MMBtu}$ and diesel fuel consumed at a rate of gal/MMBtu. At an average EUR of $3.16 \mathrm{Bcf}$, the energy cost of steel utilized is $2.21 \mathrm{TJ}$, while the energy equivalent of diesel fuel consumption is 74.74 GJ. The total energy costs realized in construction of the recovery pipeline is $2.29 \mathrm{TJ}$.

\section{Gas Processing}

Natural gas produced at the wellhead must be processed before it can be delivered to long distance pipelines. The 


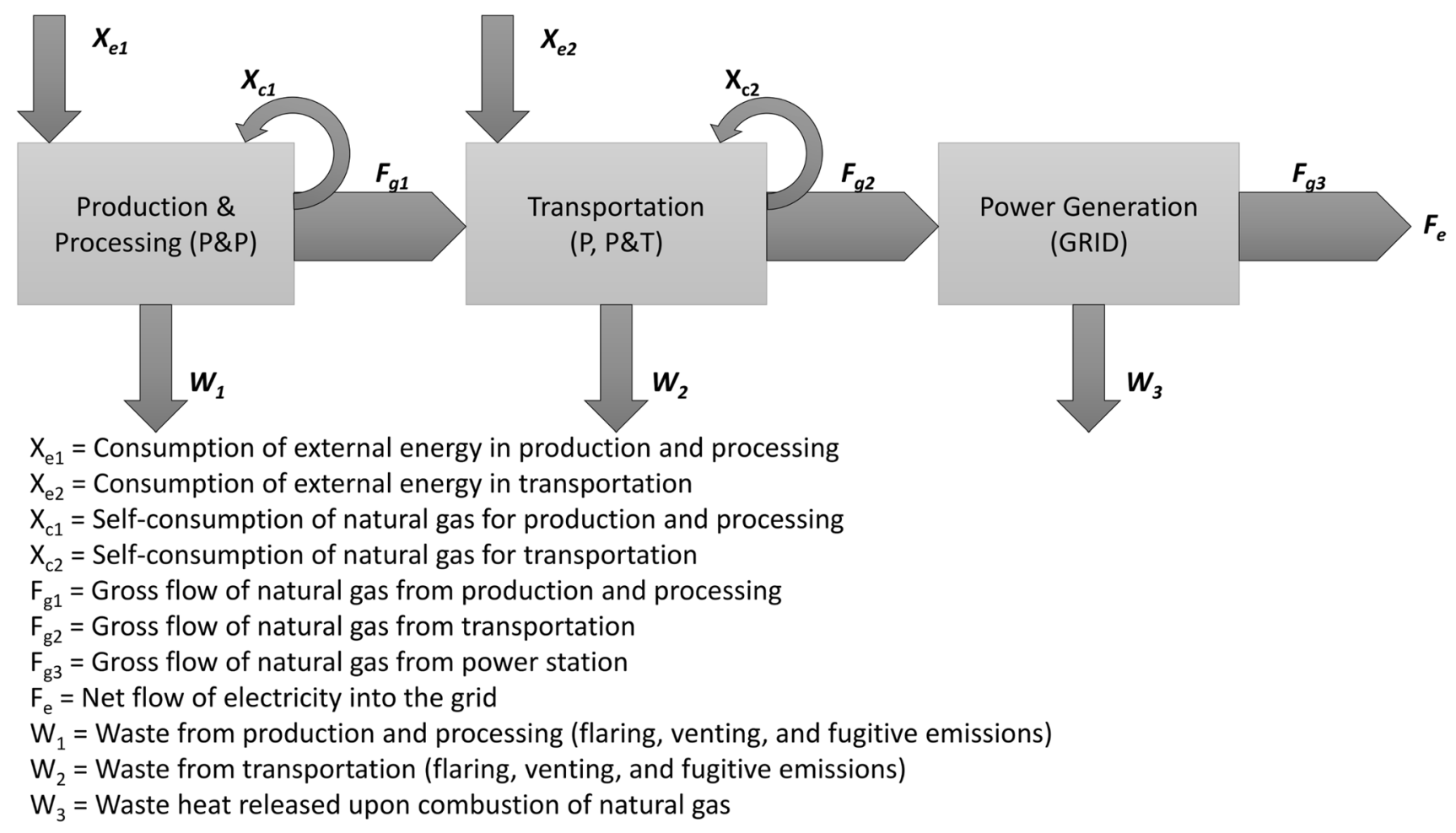

Fig. 4 Process stages in the production process

processing of wellhead natural gas generally involves gasoil separators, condensate separators and dehydration (to remove free water from the gas), contaminant removal, nitrogen extraction, and methane separation and fractionation (to process and separate natural gas liquids) (NETL 2016). The National Renewable Energy Laboratory (NREL) provides the energetic (fuel) inputs for the processing natural gas at the plant (NETL 2016). The inputs include combusted diesel fuel, electricity utilized from the grid, gasoline combustion, and natural gas and residual fuel oil combusted in the boiler. The fuel sources utilized in the processing stage are reported as an energetic cost (MJ) to treat a cubic feet of natural gas, the processing stage represents a variable energetic cost, and as such, it is a function of estimated EUR. Processing costs range from $438 \mathrm{GJ}$ for the low estimate $(0.23 \mathrm{Bcf})$ to $11.5 \mathrm{TJ}$ for the high estimate $(6.03 \mathrm{Bcf})$, and the mean EUR of $3.16 \mathrm{Bcf}$ represents a cost input of $6.01 \mathrm{TJ}$.

\section{Gas Transport}

Stephenson et al. (2011) estimate gas transport from the processing plant to the power plant at 900 miles. The average compressor station in the pipeline network is spaced every 100 miles, and eight intermediate stations are needed to transport the gas (Stephenson et al. 2011; EIA 1996). The EIA, in 2009 (EIA 2009), estimates that $1.4 \%$ of the natural gas transported through the pipeline is consumed as fuel at the compression stations. Natural gas combustion during gas transport, assuming the mean EUR value of $3.16 \mathrm{Bcf}$, is $40.11 \mathrm{TJ}$.

\section{Power Station}

According to the EIA (2009) and data used by Stephenson et al. (2011) for power generation, it assumes that natural gas is burned at an average US power station, which by 2009 the efficiency had increased to $43 \%$. However, natural gas power plant efficiencies range from 28 to $58 \%$ across the USA (Stephenson et al. 2011). Using the average efficiency value and the mean estimated EUR of $3.16 \mathrm{Bcf}$, $57 \%$ of the average well's energy content is lost through power generation, equating to an energy cost of 1633.19 TJ.

\section{Calculation of EROI}

Utilizing a hybrid LCA approach, we calculated lifetime EROI values using three distinct process stage boundaries (Fig. 4):

1. EROI $_{P \& P}$ which includes all energy costs through production and local/on-site processing (Eq. 1); 
$\mathrm{EROI}_{\mathrm{P} \& \mathrm{P}}=\frac{F_{g 1}-W_{1}}{\left(X_{e 1}+X_{c 1}\right)}$

2. EROI $_{\mathrm{P}, \mathrm{P} \& \mathrm{~T}}$ which includes all costs through production, local/on-site processing and the cost of transporting that gas to a power plant (Eq. 2), and

$\mathrm{EROI}_{\mathrm{P}, \mathrm{P} \& \mathrm{~T}}=\frac{F_{g 2}-W_{2}}{\left(X_{e 1}+X_{c 1}\right)+\left(X_{e 2}+X_{c 2}\right)}$

3. EROI $_{\text {GRID }}$ which includes all energetic costs up to and including the cost to convert natural gas into electricity at a power plant (Eq. 3).

$\mathrm{EROI}_{\mathrm{GRID}}=\frac{F_{g 3}-W_{3}}{\left(X_{e 1}+X_{c 1}\right)+\left(X_{e 2}+X_{c 2}\right)}$

\section{Energy Cost Scenario Analysis}

We performed a sensitivity analysis for the inputs according to process stages for our EROI calculations (Figs. 5, 6). For each of the process stages, we adopted minimum and maximum energy input $(\mathrm{MJ} / \mathrm{MJ})$ values based on Yaritani and Matsushima (2014) and conducted a Monte Carlo simulation, following a triangular distribution of minimum, mean, and maximum values. The minimum, mean, and maximum energetic input values were used to calculate a range of EROI results based on the estimated mean EUR value.

\section{Production Scenario Analysis}

Based on our decline curve analysis, we have generated low, average, and high production scenarios utilizing the mean cost scenarios obtained from the sensitivity analysis. The low scenario represents 0.23 Bcf EUR and includes $9 \%$ of the sampled wells falling less than one standard deviation from the mean EUR value. The mean EUR

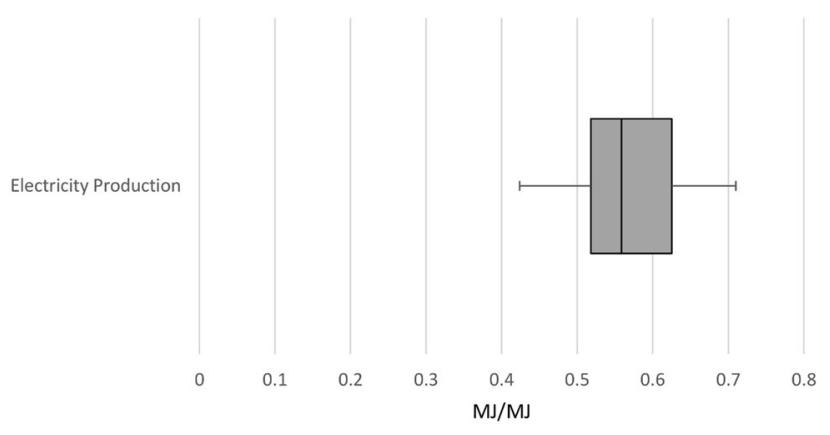

Fig. 6 Sensitivity analysis (electricity production)

scenario includes all those sampled wells within one standard deviation from the mean $(3.16 \mathrm{Bcf})$, and $79 \%$ of the wells included in the analysis fall within one standard deviation from the mean EUR value. The high scenario EUR is $6.03 \mathrm{Bcf}$ and includes $12 \%$ of the sampled wells.

\section{Results}

Our results indicate that producing electricity from shale gas has an EROI of 10, which is roughly equal to that from photovoltaics (Fig. 7). Raugei et al. (2012) report that the EROI for mono-C Si and multi-C $\mathrm{Si}$ is both 5.9, ribbon $\mathrm{Si}$ is 9.4, and CdTe thin film technology is 11.8 , while our calculations for the $\mathrm{EROI}_{\mathrm{GRID}}$ of shale gas give a range of 1.2-15.0, with an average value of 10.4.

Our results build on those of Aucott and Melillo (2013) who calculated 90 for EROI $_{\mathrm{P} \& \mathrm{P}}$ and Yaritani and Matsushima (2014) who calculated an EROI of 12 for EROI $_{\text {PP\&T }}$ (Table 6). By comparison, our values for those two EROI calculations are 40 and 25, respectively. Differences in these EROI values are due to the omission of different energy inputs in each study. For example, Aucott and Melillo (2013) omit well workovers and gas processing inputs in their analysis, while Yaritani and Matsushima
Fig. 5 Sensitivity analysis (input costs, less electricity production)

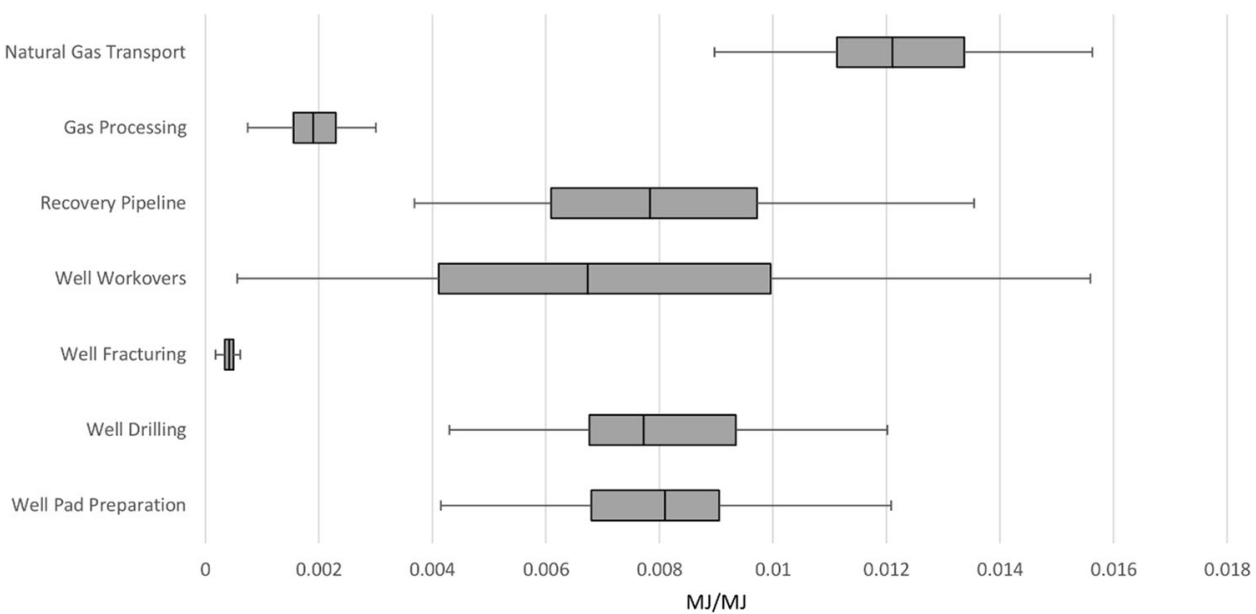


(2014) omit well workovers, recovery pipeline, and water recycling and disposal, and use a much higher value for the cost of gas processing (Table 6). To account for flaring and fugitive methane emissions, as a conservative estimate, our analysis adopted the levels published by Yaritani and Matsushima (2014). Approximately $13 \%$ of the natural gas produced is lost during the production and processing process stages, through fugitive emissions, venting, and flaring. An additional $3 \%$ is lost through the transportation process stage; these values are accounted for as waste outputs in our EROI calculations (Fig. 4). Alternatively, Aucott and Melillo (2013) subtract $8.2 \%$ of the natural gas produced to account for compression and processing.

\section{Well Initial Production Values}

The number of active wells located in the top six producing counties within the state of Pennsylvania account for $74 \%$ of the total active wells included in the data set.

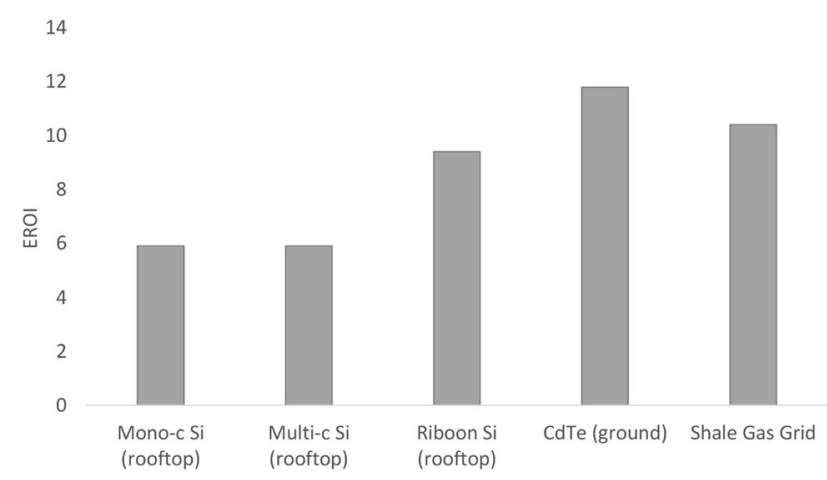

Fig. 7 Comparison of EROI values for electricity production from various resources and technologies
Susquehanna County, while ranked third in the number of active producing wells, leads the state with an average IP value of $6764.90 \mathrm{Mcf} /$ day. Further, within Susquehanna County the highest producing IP wells are geographically clustered in the rural southwestern corner of the county, at comparatively high elevation levels and generally lower degrees of slope. Analysis of IP levels indicates a significant increase in average values from period one (1855 Mcf/day) to period eight (6392 Mcf/day). Spatially, the largest IP values are clustered within six Pennsylvania counties, and the highest IP county is Susquehanna, with an average value of $6765 \mathrm{Mcf} /$ day (Table 7). At a finer scale, within each high producing county, IP values are further clustered (Fig. 8).

\section{Energy Cost Scenarios}

Due to the high cost of converting natural gas into electricity, the costs at the power plant overwhelm other inputs in our analysis, resulting in comparatively low values for EROI $_{\text {GRID }}$ regardless of whether a high- or low-cost scenario is used. The values for $\mathrm{EROI}_{\mathrm{P} \& \mathrm{P}}$ range from 18 for the high-cost scenario to 73 for the low-cost scenario. The values for $E \mathrm{ROI}_{P, P \& T}$ range from 14 for the high-cost scenario to 44 for the low-cost scenario. Finally, the values for EROI $_{\text {GRID }}$ ranged from 1.2 to 15 for the high- and lowcost scenario, respectively (Fig. 9).

\section{Production Scenarios}

Although the EROI ${ }_{\text {GRID }}$ values are comparatively low, the EROI $_{P \& P}$ and $E_{\text {ROI }}$ \&\&T values are much higher with larger ranges (Fig. 10). The weighted $\mathrm{EROI}_{\mathrm{P} \& \mathrm{P}}$ of natural gas within the Marcellus Shale of Pennsylvania is 40,
Table 6 Comparison of our EROI results to Yaritani and Matsushima (2014) and Aucott and Melillo (2013)

\begin{tabular}{|c|c|c|c|}
\hline Units & $\begin{array}{l}\text { Our analysis } \\
\text { MJ:MJ }\end{array}$ & $\begin{array}{l}\text { Yaritani and } \\
\text { Matsushima (2014) } \\
\text { MJ:MJ }\end{array}$ & $\begin{array}{l}\text { Aucott and } \\
\text { Melillo (2013) } \\
\text { MJ:MJ }\end{array}$ \\
\hline Well pad preparation & 0.009 & 0.003 & 0.0001 \\
\hline Well drilling & 0.009 & 0.004 & 0.003 \\
\hline Well fracturing & 0.0005 & 0.005 & 0.003 \\
\hline Well workovers & 0.005 & - & - \\
\hline Recovery pipeline & 0.001 & - & 0.003 \\
\hline Water recycling and disposal & - & - & 0.001 \\
\hline Gas processing & 0.002 & 0.049 & - \\
\hline Natural gas transport & 0.014 & 0.009 & 0.001 \\
\hline Electricity production & 0.570 & - & - \\
\hline Gross total & 0.610 & 0.069 & 0.012 \\
\hline $\mathrm{EROI}_{\mathrm{P} \& \mathrm{P}}$ & 39.65 & - & 90.69 \\
\hline $\mathrm{EROI}_{\mathrm{P}, \mathrm{P} \& \mathrm{~T}}$ & 24.92 & 12.05 & 81.13 \\
\hline $\mathrm{EROI}_{\mathrm{GRID}}$ & 10.72 & - & - \\
\hline
\end{tabular}


Table 7 Cumulative well counts, percentage of total wells, and average IP by county

\begin{tabular}{lllll}
\hline Rank by AIP & Well county & Number of wells & \% of total & Average IP (Mcf/day) \\
\hline 1 & Susquehanna & 670 & 13 & 6764.90 \\
3 & Lycoming & 617 & 12 & 4944.73 \\
2 & Bradford & 858 & 17 & 4905.34 \\
4 & Greene & 505 & 10 & 4466.29 \\
6 & Washington & 710 & 14 & 3277.94 \\
5 & Tioga & 450 & 9 & 2926.86 \\
\hline
\end{tabular}

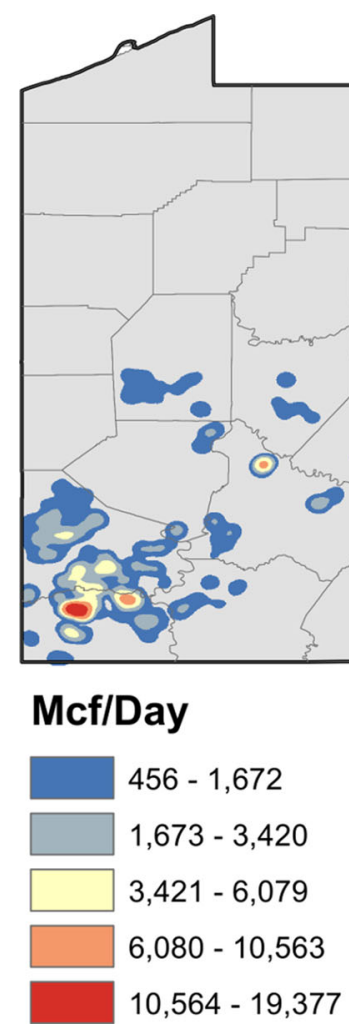

Fig. 8 Map of IP values

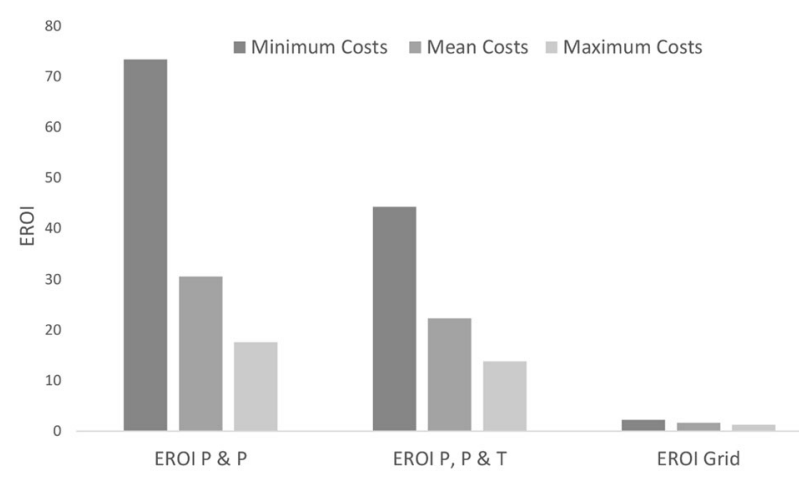

Fig. 9 EROI results stratified by both boundary of analysis and cost scenarios which means that $80 \%$ of the wells studied fall between the ranges of 3-71, while $9 \%$ are less than 3 and $12 \%$ are greater than 71 . The weighted $\mathrm{EROI}_{\mathrm{P}, \mathrm{P} \& \mathrm{~T}}$ within the Marcellus is 24, with $80 \%$ of the wells between 3 and 35, while $9 \%$ are less than 3 and $12 \%$ are greater than 35 . The weighted average of Marcellus wells at the $\mathrm{EROI}_{\mathrm{GRID}}$ is 10 , with very little variation between low, mean, and high estimates.

\section{Results by Process Stage}

Electricity production is by far the largest cost per production stage, costing $0.57 \mathrm{MJ}$ of natural gas per MJ of 


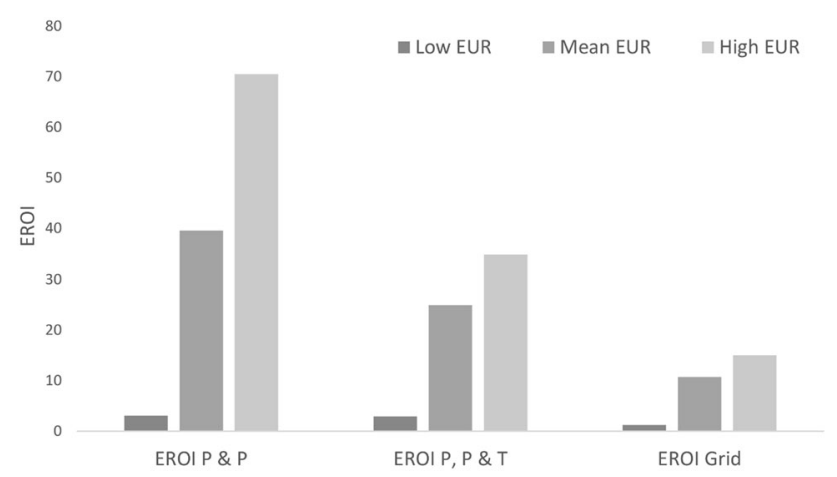

Fig. 10 EROI results stratified by both boundary of analysis and EUR scenarios

electricity produced (Table 6). Excluding electricity production, the most significant drivers of production costs are well pad preparation (0.009 MJ) and well drilling (0.009 MJ), which collectively represent $75 \%$ of total production costs (Table 6). Gas processing, as a function of EUR, represents a larger percentage of total processing and production costs for the high estimate EUR value (14\%) as compared to the mean and low estimate, 8 and $0.01 \%$, respectively. At each subsequent stage (transmission and grid), the additional energy cost represents a larger portion of the total energy cost in the process. For example, the energy cost of gas transport represents $37 \%$ of the total energy cost of the high estimate scenario, but only 25 and $3 \%$ of the total energy cost for the mean and low estimate scenarios. This is representative of the large differences in EROI $_{\text {P\&P }}$ versus the EROI ${ }_{\text {GRID }}$ for both the mean and high EUR estimates, from 71 to 2 for the high estimate EUR wells and from 40 to 2 for the mean estimate wells.

Our results by process stage are similar to those reported in both Aucott and Melillo (2013) and Yaritani and Matsushima (2014) for most process stages (Table 6). The most significant difference between our analysis and the previous studies is the inclusion of the energy costs required to produce electricity. Energy costs for most process stages are only a fraction of the total energy output except for the electricity production stage, where most of the energy is required to produce electricity.

\section{Discussion}

Our results expand on those reported in previous efforts by Aucott and Melillo (2013) and Yaritani and Matsushima (2014). For example, transportation cost values are similar in our analysis to Yaritani and Matsushima (2014), as we report a 0.014 MJ:MJ compared to 0.009 MJ:MJ for Yaritani and Matsushima (2014), but Aucott and Melillo (2013) report significantly lower measures (0.001 MJ:MJ). EROI $_{P, P \& T}$ values are impacted accordingly, 25 for our analysis compared to 12 for Yaritani and Matsushima (2014) and 81 for Aucott and Melillo (2013).

In contrast to previous research, our analysis of EROI $_{\text {GRID }}$ builds on the current literature and was a deliberate attempt to use the same functional unit (1 MJ of electricity into the grid) as analyses conducted on renewable energy technologies. In this instance, we can directly compare the energy surplus of natural gas production to that of photovoltaics (PV) (Fig. 7). Through this process, as natural gas is produced and converted into electricity, our analysis indicates that power generation accounts for $93 \%$ of the total energetic costs to provide one MJ of electricity to society. The inefficiency of natural gas power generation is the singular reason that the EROI $_{\text {GRID }}$ is lower than the various EROI values of PV summarized in this analysis (Fig. 7). Recent literature (Berstad et al. 2011; Clark and Herzog 2014; Lindqvist et al. 2014) evaluates the inefficiencies of natural gas combined cycle (NGCC) power plants. With current available technologies, theoretically the most efficient NGCC power plants can operate at $57 \%$ efficiency levels (meaning that $43 \%$ of the energy content of natural gas is lost through heat transfer) without carbon capture and storage (CCS) systems. Our model
Fig. 11 Net energy cliff graph adapted from Mearns (2008). Dark gray is the net energy, and light gray is the energy cost to produce energy

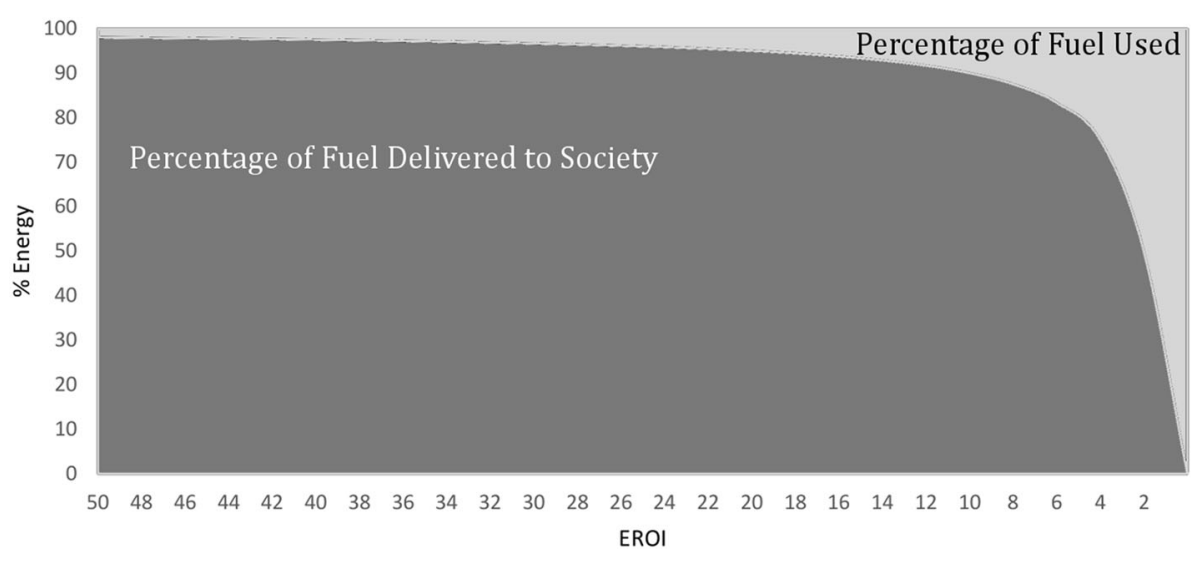


conservatively utilizes the reported average plant efficiency from Stephenson et al. (2011) of $43 \%$. Comparing the average of $43 \%$ for existing plants versus the maximum theoretical efficiency of $57 \%$ translates to an approximate $400 \mathrm{GJ}$ reduction in total energy costs for the average EUR well from our analysis and a $23 \%$ reduction in the cost to produce one $\mathrm{MJ}$ of electricity.

In this context, assessing the net energy benefit of natural gas as an electricity generating source can best exemplified through the concept of the net energy cliff (Mearns 2008), which represents net energy as a percentage of EROI values (Fig. 11). The net energy cliff describes the exponential relationship between gross energy and net energy flows and establishes the critical relationship between EROI and societal benefit. As EROI values fall below 10 , the benefit to society (of that energy source) begins to exponentially decline (Murphy 2014). Because of the already low average EROI ${ }_{\text {GRID }}$ value of natural gas, the benefit of increased plant efficiency only yields an improvement of 2.1 to our estimate of $\mathrm{EROI}_{\mathrm{GRID}}$.

\section{Summary}

By extending the boundary of shale gas analysis, our results calculate EROI in terms of the electricity output per unit of energy invested, allowing for direct comparison to renewable alternatives. This work reinforces two major criticisms levied against the future of shale production: (1) the observed steep decline rates of production and (2) power plant conversion inefficiencies. Shale gas wells often have annual decline rates well above $60 \%$, which means that new wells must constantly be developed to offset declining wells from previous years. Constant and continuous well drilling is capital intensive and unlikely to continue long into the future. These steep decline rates are also viewed by many in combination with the idea that most of the drilling thus far has been concentrated in the best areas within Shale plays and that, as drilling continues, the overall production levels will decline as more marginal areas are utilized. Indeed, even as technology improves the power generation process, electricity generation from natural gas is delivering less energetic benefit to society over time.

\section{References}

Aucott ML, Melillo J (2013) A preliminary energy return on investment analysis of natural gas from the Marcellus Shale. J Ind Ecol 17(5):668-679

Berstad D, Arasto A, Jordal K, Haugen G (2011) Parametric study and benchmarking of NGCC, coal and biomass power cycles integrated with MEA-based post-combustion $\mathrm{CO}^{2}$ capture. Energy Procedia 4:1737-1744
Brandt AR (2011) Oil depletion and the energy efficiency of oil production: the case of California. Sustainability 3:1833-1854

Brandt AR, Englander J, Bharadwaj S (2013) The energy efficiency of oil sands extraction: energy return ratios from 1970 to 2010 . Energy 55(15):693-702

Burnham A, Han J, Clark CE, Wang M, Dunn JB, Palou-Rivera I (2011) Life-cycle greenhouse gas emissions of shale gas, natural gas, coal, and petroleum. Environ Sci Technol 46(2):619-627

Carnegie-Mellon (2010) Economic input-output life cycle assessment. 2009 December 8, 2010

Choate WT (2003) Energy and emission reduction opportunities for the cement industry. In: Energy and emission reduction opportunities for the cement industry. BCS, Incorporated

Clark V, Herzog H (2014) Assessment of the US EPA's determination of the role for $\mathrm{CO}^{2}$ capture and storage in new fossil fuel-fired power plants. Environ Sci Technol 48:7723-7729

Clark CE, Han J, Burnham A, Dunn JB, Wang M (2011) Life-cycle analysis of shale gas and natural gas (No. ANL/ESD/11-11). Argonne National Laboratory (ANL)

Clark CE, Horner RM, Harto CB (2013) Life cycle water consumption for shale gas and conventional natural gas. Environ Sci Technol 47(20):11829-11836

Cleveland C (2005) Net energy from the extraction of oil and gas in the United States. Energy 30:769-782

EIA (1996) US Energy Information Administration. Methane Emissions from the Natural Gas Industry, Volume: 7 Blow and Purge Activities, 1996. http://www.epa.gov/gasstar/documents/emis sions_report/7_blowandpurge.pdf

EIA (2009) US Energy Information Administration. Combined (Utility, Non-Utility, and Combined Heat and Power Plant) Database, 2009. http://www.eia.gov/Ftproot/pub/electricity/ f923_2009.zip

EIA (2015) US Energy Information Administration, Annual Energy Outlook 2015. http://www.eia.gov/forecasts/aeo/

Gagnon N, Hall CAS, Brinker L (2009) A preliminary investigation of the energy return on energy invested for global oil and gas extraction. Energies 2:490-503

Guilford MC, Hall CAS, O'Connor P, Cleveland CJ (2011) A new long term assessment of energy return on investment (EROI) for US oil and gas discovery and production. Sustainability 3:1866-1887

Hall CAS, Cleveland CJ, Berger M (1981) Energy return on investment for United States petroleum, coal, and uranium. In: Energy and ecological modeling, pp 715-724

Hall CA, Balogh S, Murphy DJ (2009) What is the minimum EROI that a sustainable society must have? Energies 2(1):1-25

Jiang M, Griffin WM, Hendrickson C, Jaramillo P, VanBriesen J, Venkatesh A (2011) Life cycle green house gas emissions of Marcellus Shale. Environ Res Lett 6(3):034014

Lindqvist K, Jordal K, Haugen G, Anders Hoff K, Anantharaman R (2014) Integration aspects of reactive adsorption for postcombustion $\mathrm{CO}_{2}$ capture from NGCC (Natural Gas Combines Cycle) power plants. Energy 78:758-767

Mearns E (2008) The global energy crises and its role in the pending collapse of the global economy. Royal Society of Chemists, Aberdeen, Scotland

Murphy DJ (2014) The implications of the declining energy return on investment of oil production. Philos Trans R Soc Lond A Math Phys Eng Sci 372(2006):20130126

Murphy DJ, Hall CAS, Powers B (2011) New perspectives on the energy return on (energy) investment (EROI) of corn ethanol. Environ Dev Sustain 13(1):179-202

National Renewable Energy Laboratory (NETL) (2016) Data discovery: details for natural gas processed at plant. https://www. lcacommons.gov/nrel/process/show/40390?qlookup $=\& \max =35$ \&hfacet $=\&$ hfacetCat $=\&$ loc $=\&$ year $=\&$ dtype $=\&$ crop $=\&$ index $=29$ \&numfound $=3160 \&$ offset $=$ 
PA DEP. Pennsylvania Department of Environmental Protection. Oil and Gas Reporting Web Site. http://www.paoilandgasreporting. state.pa.us/publicreports/moduels/welcome/agreement.aspx

Raugei M, Fullana-i-Palmer P, Fthenakis V (2012) The energy return on energy investment (EROI) of photovoltaics: methodology and comparisons with fossil fuel life cycles. Energy Policy 45:576582

Sell B, Murphy D, Hall CAS (2011) Energy return on energy invested for tight gas wells in the Appalachian Basin, United States of America. Sustainability 3(10):1986-2008

Stephenson T, Valle JE, Riera-Palou X (2011) Modeling the relative GHG emissions of conventional and shale gas production. Environ Sci Technol 45:10757-10764
Stokes J, Horvath A (2006) Life cycle energy assessment of alternative water supply systems. Int $\mathrm{J}$ Life Cycle Assess 11(5):335-343

Stubbles JR (2000) Energy Use in the US steel industry: historical perspective and future opportunities. Office of Industrial Technologies, US Department of Energy, Washington

Wang M (2008) The greenhouse gases, regulated emissions, and energy use in transportation (GREET) Model: Version 1.5. Center for Transportation Research, Argonne National Laboratory

Yaritani H, Matsushima J (2014) Analysis of the energy balance of shale gas development. Energies 7:2207-2227 